\title{
The impact of dams on the river connectivity of the two largest river basins in China
}

\author{
Yujun $\mathrm{Yi}^{1}$, Yanning Gao ${ }^{1}$, and Shanghong Zhang ${ }^{2}$ \\ ${ }^{1}$ Beijing Normal University \\ ${ }^{2}$ North China Electric Power University
}

June 15, 2020

\begin{abstract}
Dams are built on rivers to make effective use of, inter alia, water resources, flood protection, and power generation. The construction of dams has greatly promoted the economy and social development, but also reduced the connectivity of rivers, which leads to the weakening of the exchange of material and biological organisms between rivers. The connectivity of rivers directly determines the self-purification and pollution capacity of water bodies, and the migration possibility of fish, which are all important indexes for quantifying the ecological health in basins. In this study, the connectivity of the two largest river basins in China, the Yangtze River and Yellow River Basins, was investigated. The Dendritic Connectivity Index (DCI) was applied to evaluate the impact on river connectivity of dams with a reservoir capacity of larger than $100 \mathrm{million}$ m3. The results show that river connectivity decreased as dam construction increased. The connectivity of the Yangtze River Basin was good in the 1980s, but declined significantly after the Gezhouba Dam was constructed on the mainstream. The changes in the connectivity indexes of potadromous fish (DCIp) and diadromous fish (DCId) were determined for the period of 1980-2010. In the Yangtze River Basin, the DCIp decreased by $58 \%$ (from 81.25 to 34.16 ) and the DCId decreased by $53 \%$ (from 89.98 to 42.30). In the Yellow River Basin, the DCIp decreased by $38 \%$ (from 51.46 to 31.81) and the DCId decreased by $60 \%$ (from 32.74 to 13.00). In both basins, dams on the mainstream are the main cause of the decline in the DCI, dams located on the middle reaches are the main cause of the decline in the DCIp, and dams located on the lower reaches close to the estuary are the main cause of the decline in the DCId.
\end{abstract}

Novelty and International Appeal Statement

To assess the impact of dams on the Yangtze and Yellow River basins, we used the Dendritical Connectivity Index (DCI) to evaluate the impacts of past and existing dams on basin connectivity by providing fish possibilities, and obtained the connectivity changes of the two basins over a 30-year period. Our novelty lies in the quantitative calculation of the impact of dam location and the efficiency of fish possibilities on the basin connectivity, and the analysis of where dams have the greatest impact on connectivity and the feasibility of constructing fishways.The results of our study will enable scholars to better understand the connectivity changes of the Yangtze river basin and the Yellow River Basin under the influence of the dam, and to determine the influence degree of the dam location and fish passage, which is crucial for the evaluation of future development strategies.

\section{Hosted file}

Title Page.docx available at https://authorea.com/users/333224/articles/459449-the-impactof-dams-on-the-river-connectivity-of-the-two-largest-river-basins-in-china

\section{Hosted file}


The impact of dams on the river connectivity of the two largest river basins in China.docx available at https://authorea.com/users/333224/articles/459449-the-impact-of-dams-on-theriver-connectivity-of-the-two-largest-river-basins-in-china
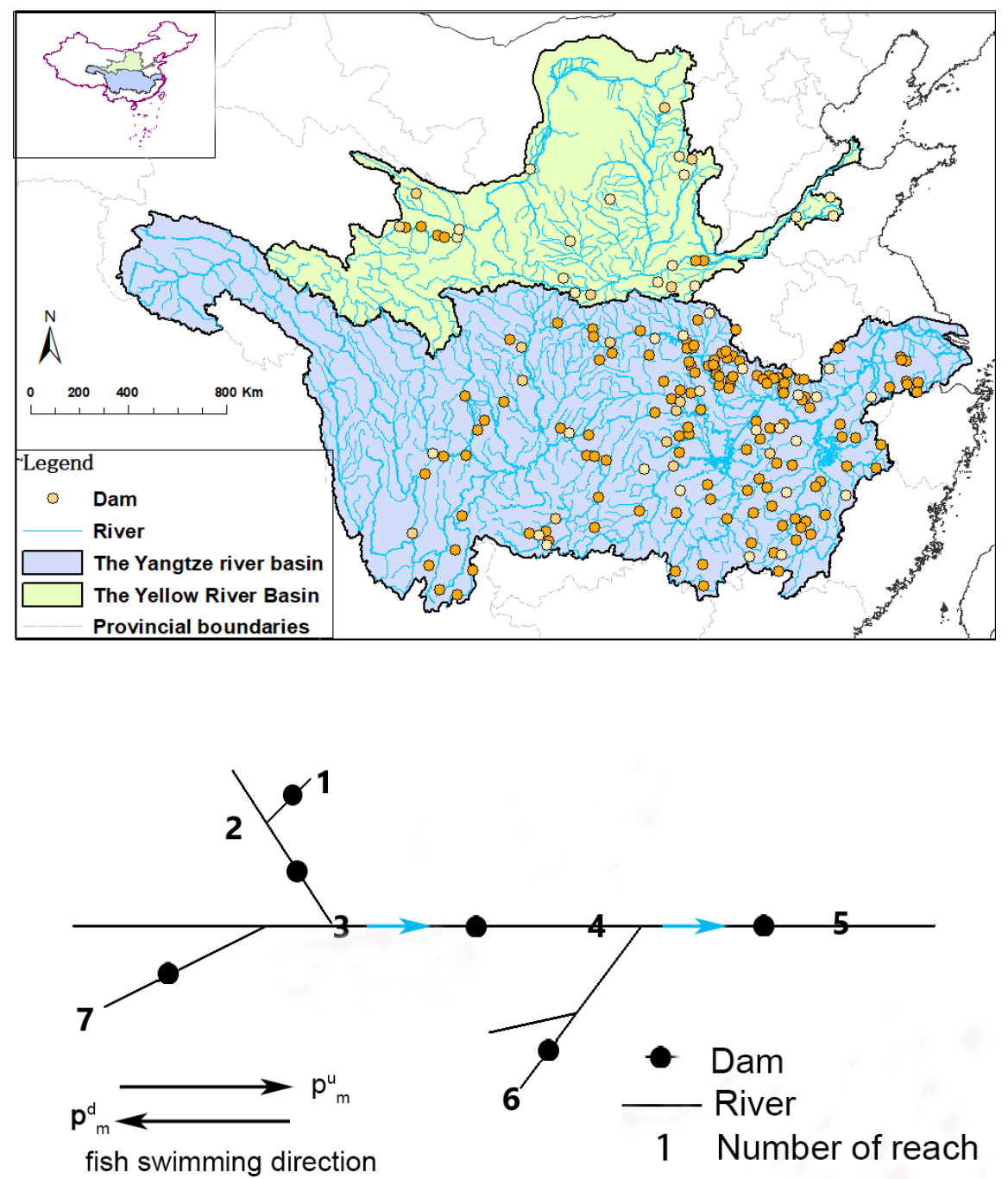
(a)
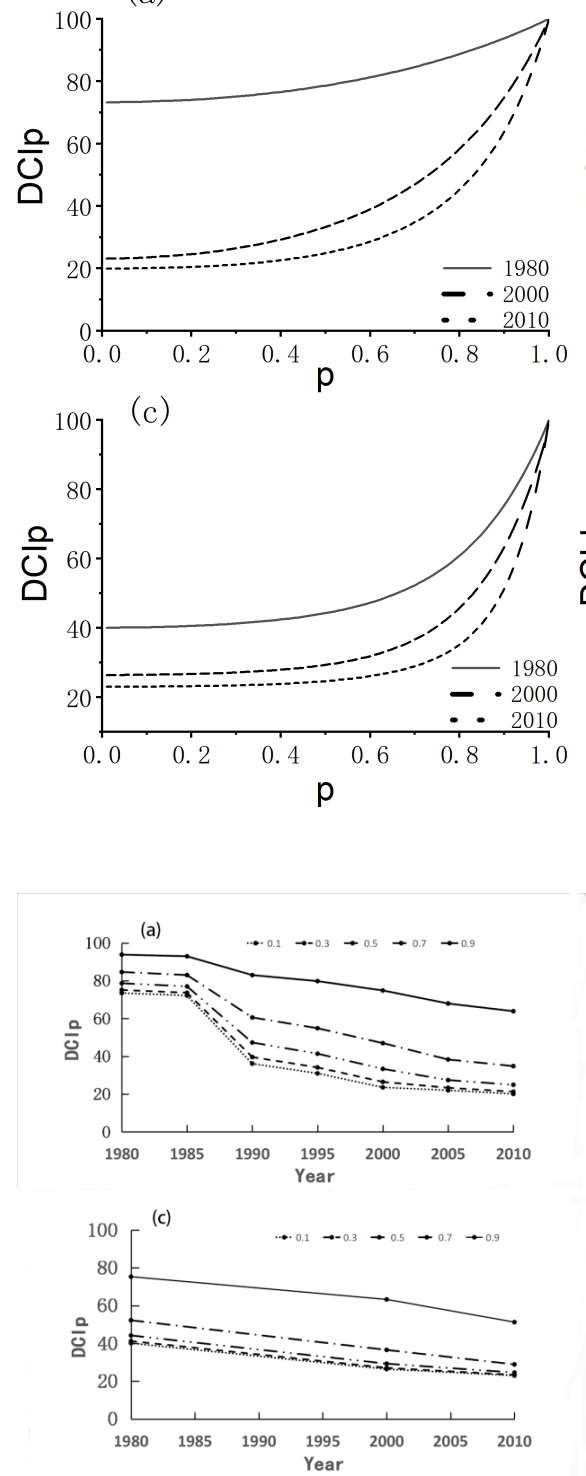

(b)
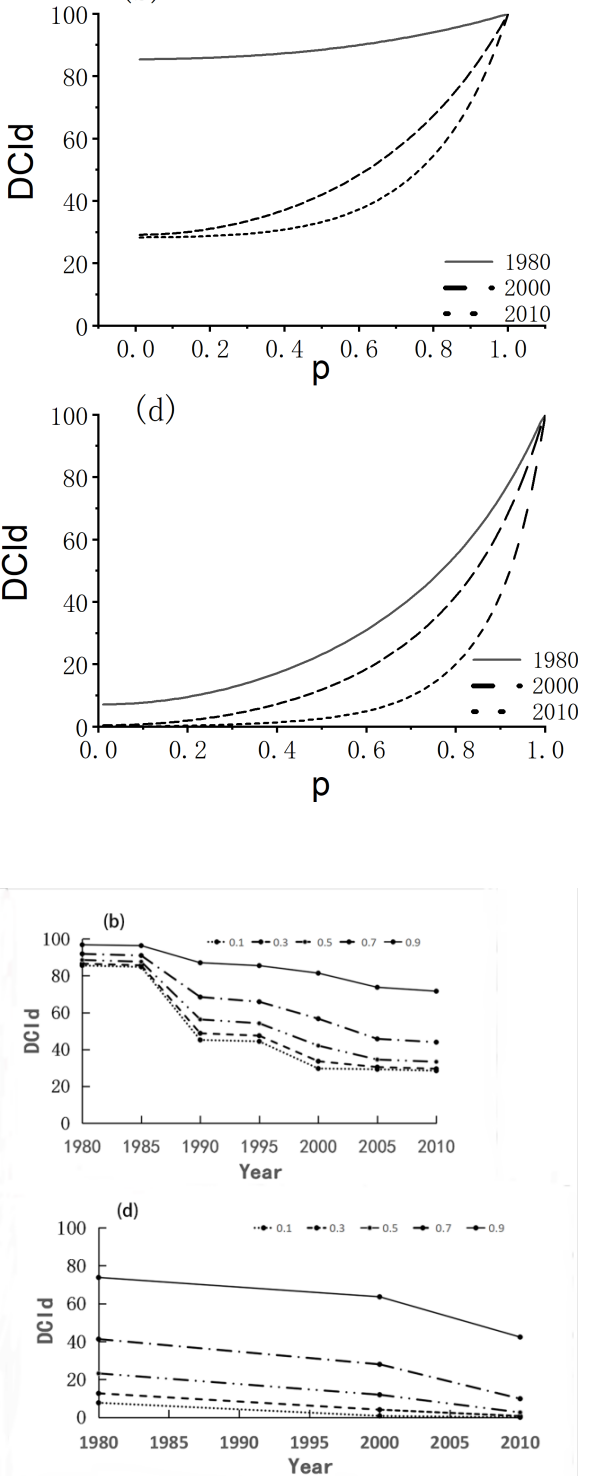

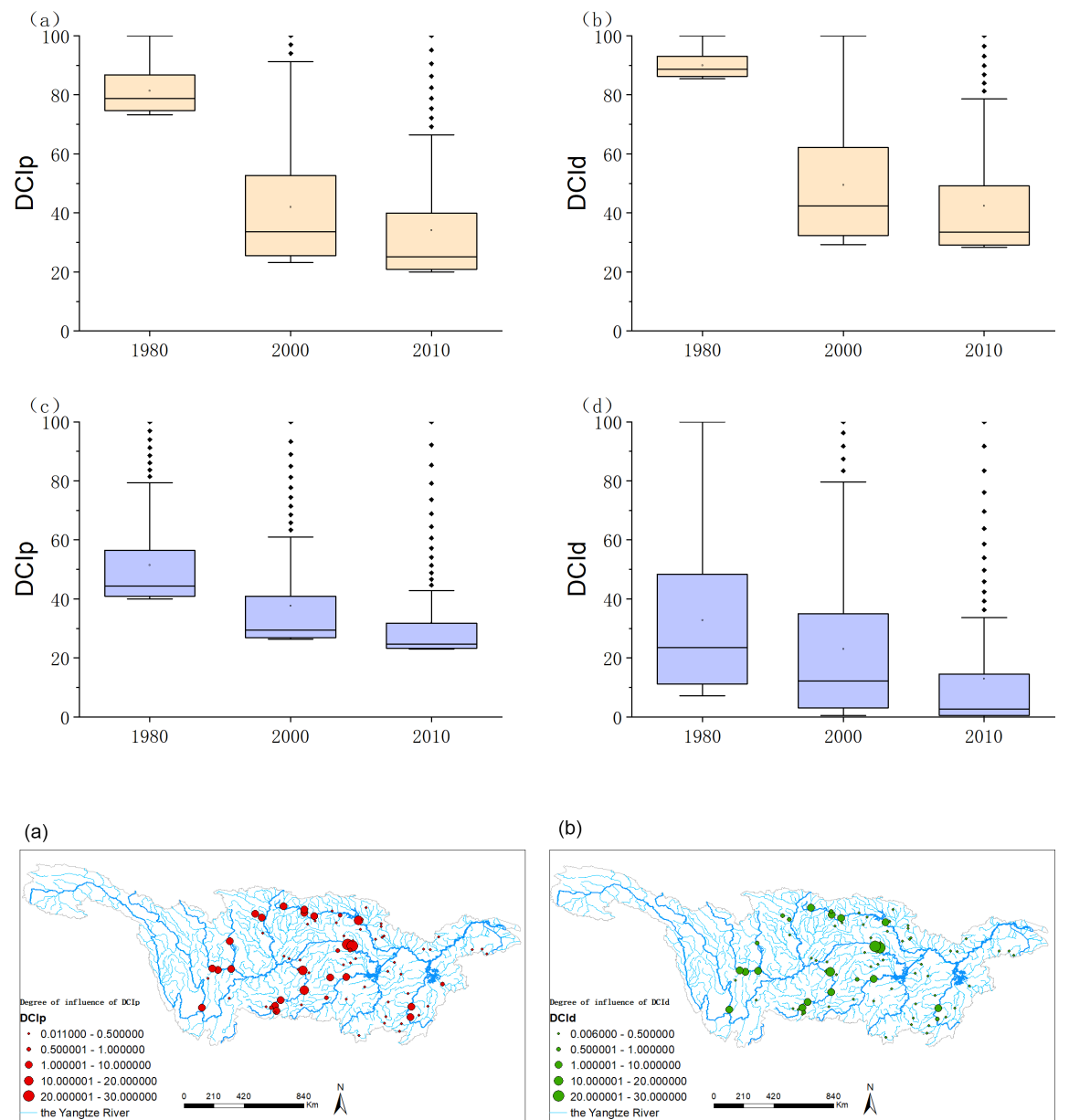

(c)

(d)
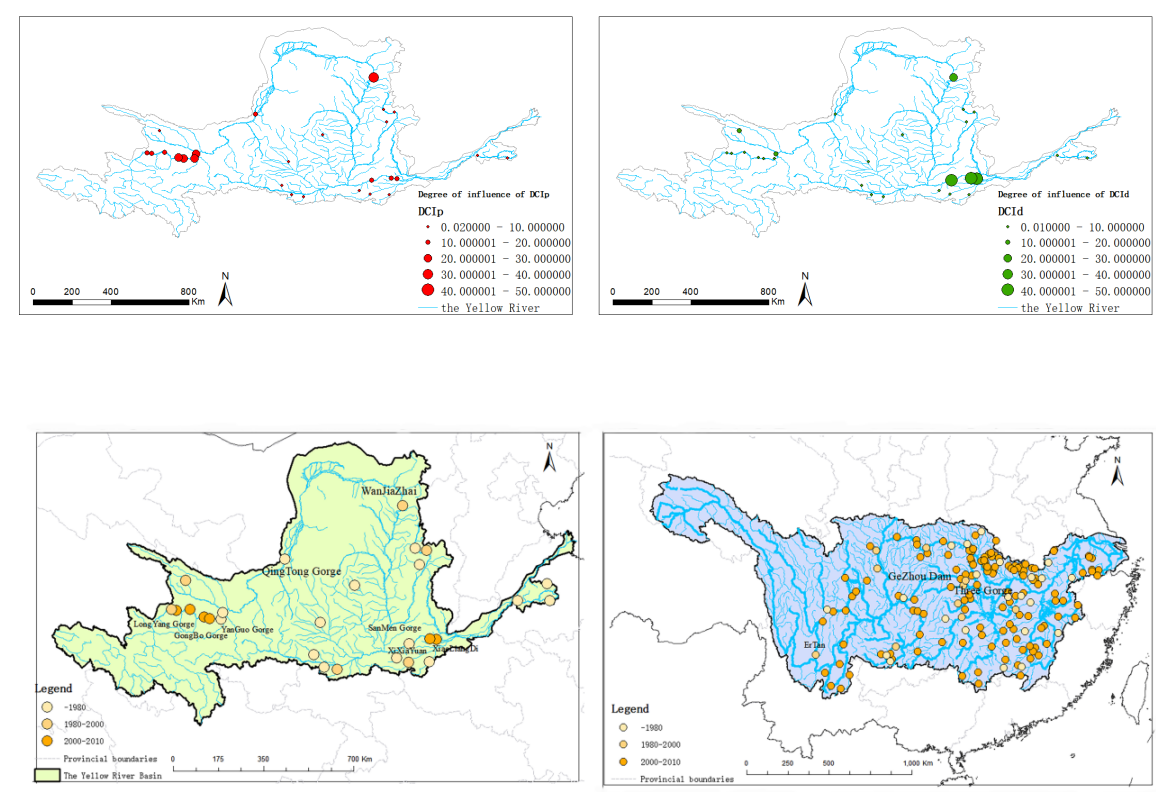

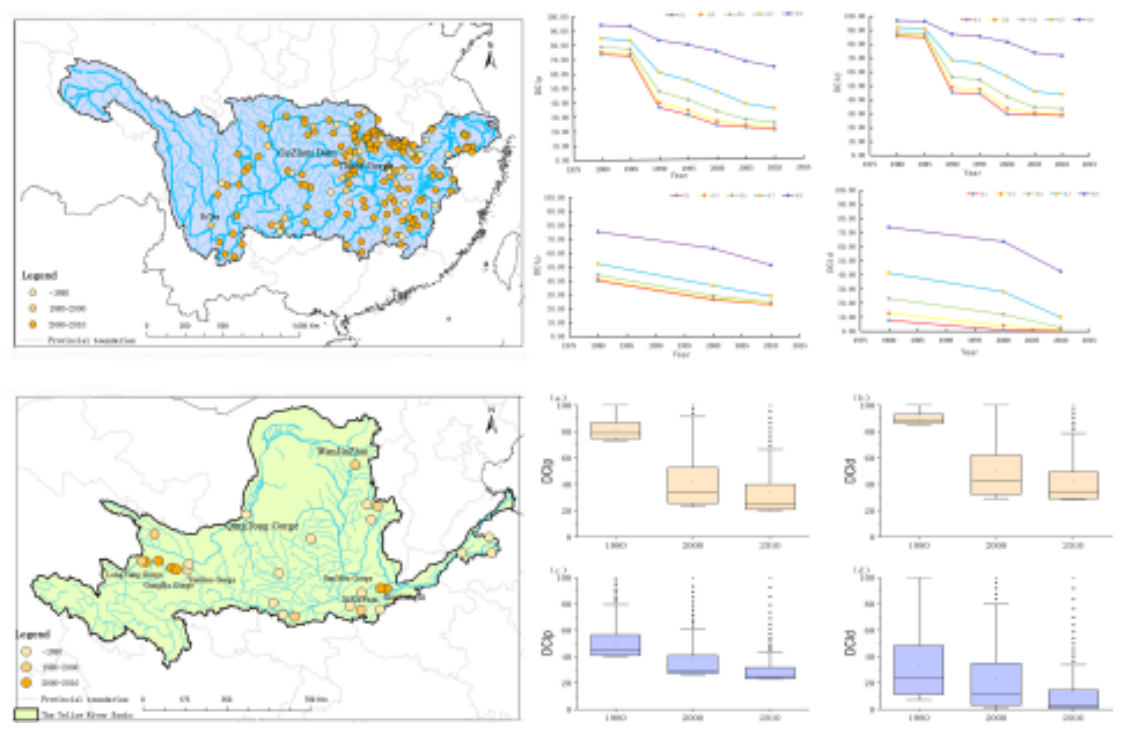